\title{
THREE-YEAR OUTCOME OF PEDIATRIC DACRYOCYSTORHINOSTOMY FOR TREATMENT OF CONGENITAL NASOLACRIMAL DUCT OBSTRUCTION
}

\author{
Abozaid, $\mathbf{M}{ }^{1{ }^{(*)}}$ \& Abdelmonem, M. $^{2}$ \\ ${ }^{1}$ Ophthalmology dept., Faculty of Medicine, Sohag Univ., Sohag, Egypt \\ ${ }^{2}$ ENT, Faculty of Medicine, Sohag Univ., Sohag, Egypt \\ *E-mail:mourtada_abdelaal@med.sohag.edu.eg
}

Received 3/7/2018

Accepted 15/10/2018

\begin{abstract}
Purpose: to retrospectively compare the success rates of external and endoscopic dacryocystorhinostomy (DCR) surgery performed for congenital nasolacrimal duct obstruction. Methods: 79 patients with congenital nasolacrimal duct obstruction that had either external DCR (41, group 1) or endoscopic DCR (38, group 2) and completed 3 year duration after surgery were included in this study. Results: 38 patients in group $1(92.7 \%)$ and 30 patients in group 2 (78.9\%) showed success of surgery after 3 years of surgery, defining success as relief of symptoms plus endoscopic visualization of the patent stoma ( $p$ value 0.079). Conclusion: Although the endoscopic approach of pediatric DCR has the advantages of the lack of skin incision, the preservation of the pump mechanism and the ability to address other nasal pathologies at the time of surgery, the external approach looks more successful on the long run.
\end{abstract}

Keywords: Congenital epiphora, External DCR, endoscopic DCR

\section{Introduction}

Congenital epiphora is a common condition, affecting up to $20 \%$ of all newborn. It is usually caused by incomepletecanalisation of the lower end of the nasolacrimal duct with persistence of a membranous web at the level of the Hasner's valve which is known as common congenital nasolacrimal duct obstruction (CNLDO). However, more than $90 \%$ of these obstructions resolve spontaneously by the end of the first year of life [1]. Nasolacrimal probing and irrigation is successful in most of the obstructions that persist after one year of age and the success rate of this maneuver is inversely related to the age of the child. The success rate at the age one year is $92 \%$ while the rate at age of 18 months or older is $50 \%$ [2]. Pediatric DCR is indicated in when a common CNLDO is unresponsive to more conservative lines of treatment such as probing, intubation or balloon dacryoplasty or when associated with a mucocele or recurrent dacryocystitis [3]. Such cases have been treated for a long time by external dacryocystorhinostomy (EXT-DCR). However, the endonasal endoscopic dacryocystorhinostomy has become widely used nowadays [4].The reported success 
for pediatric external DCR has ranged from $83 \%$ [5] to $96 \%$ [6]. In 2015, we published the results of endonasal endoscopic DCR compared to the external approach in children with congenital nasolacrimal duct obstruction after a 6 month follow

\section{Materials and methods}

A retrospective comparative study was carried out at both the ophthalmology department of Sohag university

\subsection{Materials}

Seventy nine children with congenital nasolacrimal duct obstruction were included in this study. Diagnosis of NLD obstruction depended on clinical examination in addition to NLD probing and sac syringing under general anesthesia. The inclusion criteria included patients less than 18 years of age with congenital nasolacrimal duct obstruction and failed previous probings, lacrimal mucocele or recurrent dacryocystitis. The exclusion criteria included cases with canalicular obstruction, lacrimal fistula or previous

\subsection{Surgical technique}

Hypotensive general anaesthesia was used in all surgeries. The patient was positioned supine and draped to show the nose and affected eye in the operative field.

\subsubsection{External DCR}

External DCR was performed through a small $2 \mathrm{~cm}$ paranasal skin incision. After division of the medial palpebral ligament, the lacrimal sac is opened and its medial wall is excised. A large osteotomy was created in the middle meatus, silicone up period [7]. In this retrospective comparative study, we assessed the 3year results of pediatric DCR comparing the external versus endoscopic approaches.

hospital and the ENT department of Sohag university hospital in the period between January 2014 to March 2018.

DCR in addition to children less than one year of age. Written informed consent from the parents after explanation of the risks and benefits of the surgery was obtained in all cases and the study was approved from ethical committee of Sohag faculty of medicine. The patients were divided into two groups; the first group (41 patients) included patients who underwent external DCR and the second group (38 patients) included those who underwent endoscopic DCR.

For adequate decongestion, the nasal cavity and middle meatus were packed with xylometazoline $\mathrm{HCl}$ 0.05\% (Afrin) 10 minutes before surgery.

tube insertion was done and mucosal anastomosis was achieved by suturing the anterior mucosal flaps only. Skin was then closed with absorbable interrupted sutures, fig. (1).

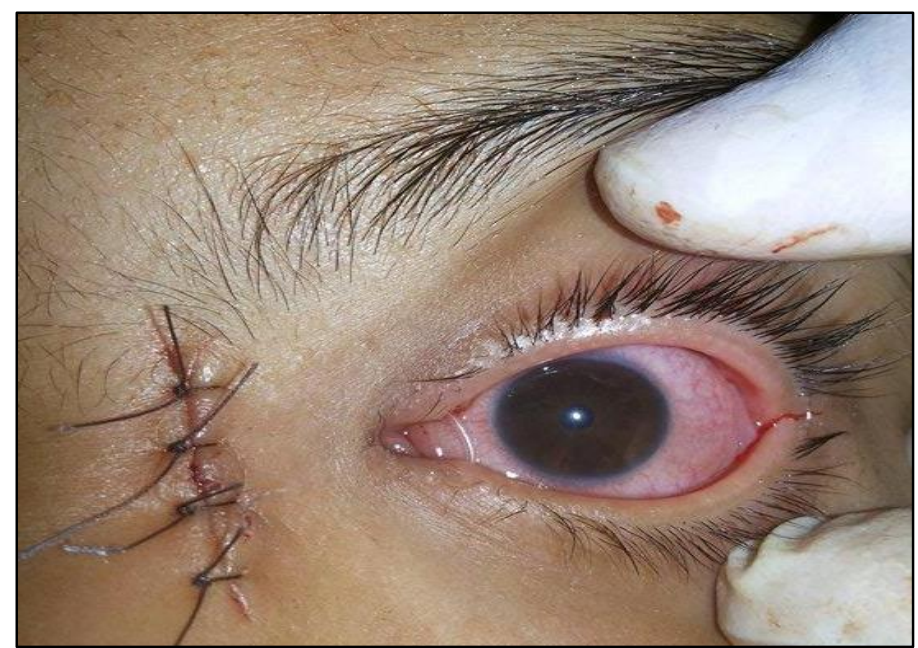

Figure (1) A case of external DCR at the end of surgery with silicone tube in place. 


\subsubsection{Endoscopic DCR}

Endoscopic DCR was performed using zero and/or 30 degrees nasal endoscopes with 2.7 and/or $4 \mathrm{~mm}$ diameter. The surgery starts with injecting the submucosa of the lateral nasal wall just anterior to the attachment of the middle turbinate with $2 \%$ lidocaine $\mathrm{HCl}$ with epinephrine 1:100:000.A mucosal incision was done using a sickle knife starting at the axilla of the middle turbinate. This incision is brought anterior to the axilla for approximately $1 \mathrm{~cm}$ and then extended inferiorly and posteriorly to the insertion of the uncinate process. A Freer elevator is used to lift the mucosal flap to expose the lacrimal bone and part of frontal process of maxilla. The bone covering the lacrimal sac is removed using drill to create a $1.0-1.5 \mathrm{~cm}$ window exposing the medialwall of the sac. The medial wall of the sac is then removed by Blakesley forceps. Patency of the opening is confirmed by sac syringing and the free flow of irrigating fluid seen by the endoscope. Silicone tube insertion was done, fig. (2) and the patient was discharged on the following day after nasal suction.

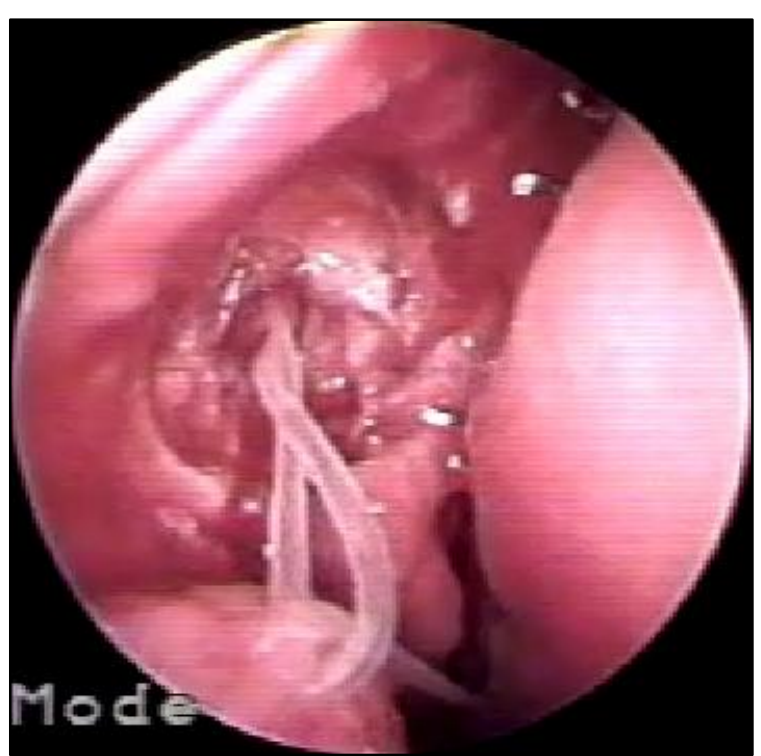

Figure (2) Endoscopic view of endonasal DCR showing the passage of the silicone tube into the nasal cavity

\subsubsection{Postoperative care}

Combined steroid-antibiotic eye drops are given for 10 to 14 days after surgery and nasal wash is done for those who had endoscopic surgery. Patients were followed every month for 6 months and

\section{Results}

Seventy nine children with congenital NLD obstruction (35 males, 34 females) that underwent DCR surgeries; 41 external (group 1) and 38 endoscopic (group 2) were included in this retrospective study. The mean age was $5.6 \pm 3.2$ years and the age range was 4 to 14 years. There was no recorded significant intraoperative complication apart from 2 cases then every 6 months for 3 years. The silicone tube was removed at the outpatient clinic after 3 months using topical anesthesia.

of profuse bleeding in group 1 that required a temporary compression before surgery could be continued. Postoperative complications included 2 patients in group 1 with nasal bleeding in the first postoperative day (the bleeding resolved with nasal packing for 24 hours), 3 patients in group 2 with pyogenic granuloma that was treated with cauterization. No 
cases of sump syndrome, cerebrospinal fluid leak, orbital tissue damage, or uncontrolled bleeding were recorded. Only patients who completed 3 year period of follow-up were included in this study. Successful outcome is defined as relief of symptoms plus endoscopic visualization of the patent stoma made into the lacrimal sac during sac irrigation. Accordingly, 38 patients in group $1(92.7 \%)$ and 30 patients in group $2(78.9 \%)$ showed success of surgery after 3 years of follow-up. The

\section{Discussion}

Congenital nasolacrimal duct obstruction is the most common cause of epiphora infants and young children. It resolves spontaneously in 85: $96 \%$ of cases by the age of 1 year [8]. Most authors agree that lack of tearing 3 months after lacrimal surgery is a good index of successful surgery [9]. In addition, many authors consider monitoring the rhinostomy opening via postoperative endoscopy [10]. External DCR has been the gold standard approach of pediatric DCR for a long time, but endoscopic DCR has recently replaced external approach widely because of many advantages which include lack of skin incision, preservation of the lacrimal pump mechanism, less bleeding, the possibility to deal with any nasal or paranasal sinus pathology at the time of surgery, and faster rehabilitation [1113]. While the disadvantages include longer operative time than external DCR, technical problems, and specific instrumentation [14-15]. Endonasal DCR complications include damage to the nasal mucosa with scar formation, perirhinostomy granuloma, orbital fat prolapse, transient damage to the medial rectus muscle with diplopia, secondary canalicular stenosis, canalicular cheesewiring by the silicone stent, sump syndrome, recurrence of lacrimal mucocele, and adhesions between the ostium and the septum [16]. External DCR is technically much success difference between the 2 groups is statistically insignificant ( $p \quad 0.079$ using chi square test). Of the 11 failed cases, obstruction at the fistula site was found in 5 cases ; 1 in group 1 and 4 in group 2, while functional failure with no evidence of obstruction was found in 6 cases; 2 in group 1 and 4 in group 2 . Endoscopic revision DCR was done in the 5 cases with anatomic obstruction and was successful in 3 cases while the remaining 2 cases had required two endoscopic revisions to have success.

easier, with a good view of the operative fieldand well-defined anatomical landmarks allowing fashioning of a wide osteotomy opening and the suturing of mucosal flaps to obtain an epithelialized DCR fistula to reduce the chance of postoperative scarring and stenosis [16-18]. Potential complications of external DCR include bruising, wound infection, cerebrospinal fluid leaking, punctual eversion, inadvertent incision of periorbita. Our prospective study published in 2015, compared endoscopic and external DCR over a relatively short period (6 months) and concluded that the 2 approaches are equally effective in children with congenital NLD obstruction [7]. However, this study that included a larger number of cases and longer postoperative duration (3 years) suggests that endoscopic DCR offers less success rate -on the long term- than external DCR in managing children with congenital NLD obstruction. Although the difference in success rate between the 2 maneuvers does not reach the 0.05 limit of statistical significance, increasing the number of patients included in the study may further decrease the $\mathrm{p}$ value. Barnes et al. did 134 external DCR surgeries to 121 child with congenital nasolacrimal duct obstruction resistant to lacrimal intubation. They reported very good results with 96 $\%$ of patients having complete cure of symptoms [19]. Although Welham and 
Hughes reported $90 \%$ overall functional success of 160 external DCR surgeries in children, most of these patients had dacryocystitis and only 34 children had congenital nasolacrimal duct obstruction [20]. Bernal-Sprekelsen et al. study in a series of 24 children on 31 sides showed good results from primary endonasal endoscopic DCR with a patencyrate of $90.3 \%$ which improved to $100 \%$ after a revision however, 28 out of 31 sides remained patent at 1 year of follow-up [21]. Unlike the above three studies, this study is retrospective, with longer duration, included only children with congenital nasolacrimal obstruction resistant to lacrimal probing and showed relatively poor outcome of endoscopic surgery compared to the external DCR.

\section{Conclusion}

Long term follow up of children that had DCR surgery for congenital NLD Obstruction revealed that the external approach is more successful than the endoscopic one

\section{References}

1. Petersen, R., Robb, R. The natural course of congenital obstruction of the nasolacrimal duct, J. Pediatr. Ophthalmol. Strabismus 1978; 15: 246-250.

2. Katowitz, J., Welsh, M. Timing of initial probing and irrigation in congenital nasolacrimal duct obstruction, Ophthalmology 1987; 94 (6): 698-705.

3. Struck, H., Weidlich, R. Indications and prognosis of dacryocystorhinostomy in childhood. A clinical study 1970 2000, Ophthalmologe 2001; 98 (6): 560-563.

4. Cunningham, M. Endoscopic management of pediatric nasolacrimal anomalies, Otolaryngol. Clin. North Am. 2006; 39: 1059-1074.

5. Nowinski, T., Flanagan, J., Mauriello, J. Pediatric dacryocystorhinostomy, Arch. Ophthalmol. 1985; 103 (8): 12261228.

6. Hakin, K., Sullivan, T., Sharma, A., Welham, R. Paediatric dacryocystorhinostomy. Aust N Z J Ophthalmol 1994; 22: 231-235.

7. Abozaid, M., Othman, Y. External versus endoscopic dacryocystorhinostomy for congenital nasolacrimal duct obstruction. J Egypt Ophthalmol Soc 2015; 108:148-152.

8. MacEwen, C., Young, J. Epiphora during the first year of life, Eye 1991; 5: 596-600.
9. Yung, M., Hardman-Lea, S. Analysis of the results of surgical endoscopic dacryocystorhinostomy: effect of the level of obstruction. Br J Ophthalmol 2002; 86: 792- 794.

10. Olver, J., Minasian, M. Nasal endoscopy for ophthalmologists. $\boldsymbol{C M E} \boldsymbol{J}$ Ophthalmol 1998; 2: 73-77.

11. Mahapankar, J., Bradoo, R., Joshi, A., Kapoor, N., Ahuja, A. Endoscopic dacryocystorhinostomy: An analysis of 16 patients, Bombay Hospital Journal 2002; 44 (1): 21-25.

12. Kamel, R., El-Deen, H., El-Deen, Y., El-Hamshary, M., Assal, A., Farid, M., et al. Manometric measurement of lacrimal sac pressure after endoscopic and external dacryocystorhinostomy. Acta Otolaryngol 2003; 123: 325329.

13. Nussbaumer, M., Schreiber, S., Yung, M. Concomitant nasal procedures in endoscopic dacryocystorhinostomy. J LaryngolOtol 2004; 118: 267-269.

14. McDonogh, M., Meiring, J. Endoscopic transnasal dacrocystorhinostomy. $\boldsymbol{J}$. LaryngolOtol 1989; 100: 585-587.

15. Moore, W., Bentley, C., Olver, J. Functional and anatomic results after two types of endoscopic endonasaldacryocystorhinostomy: Surgical and holmium laser. Ophthalmology 2002; 109: 1575-1582.

16. Dolman, P. Comparison of external dacryocystorhinostomy with nonlaserendonasal dacryocystorhinostomy. Ophthalmology 2003; 110: 78-84. 
17. Goldberg, R. Endonasal dacryocystorhinostomy: Is it really less successful? Arch Ophthalmol 2004; 122: 108-110.

18. Durvasula, V., Gatland, D. Endoscopic dacryocystorhinostomy: Long-term results and evolution of surgical technique. J LaryngolOtol 2004; 118 : 628-632.

19. Barnes, E., Abou-Rayyah, Y., Rose, G. Pediatric dacryocystorhinostomy for nasolacrimal duct obstruction. Ophthalmology 2001; 108: 15621564.

20. Welham, R., Hughes, S. Lacrimal surgery in children. Am J Ophthalmol 1985; 99: 27-34.

21.Bernal Sprekelsen, M., Massegur, H., Tomas, M. Endoscopicsinus surgery in children. Rev LaryngolOtolRhinol 2003; 124: 245-250. 